\title{
The Storm of Strongyloides stereoralis in Stool
}

Aashish Choudhary', Nitin Gupta', Hafiz Ahmad', Bijay Ranjan Mirdha'

'Department of Microbiology, All India Institute of Medical Sciences, New Delhi; ${ }^{2}$ Infectious

Disease Division, Department of Medicine and Microbiology, All India Institute of Medical Sciences, New Delhi- 110029 , India.

Abstract:

A 35-year-old male presented with complaints of intermittent diarrhea since last three months. He was a known HIV positive case for last four years. Examination of the normal saline mount of stool sample revealed multiple motile rhabditiform larvae of Strongyloides stercoralis with a count of $>100$ per low power field. They were identified by their short buccal capsule and the prominent genital primordium. The patient was successfully treated with ivermectin. We report this case to demonstrate the unusually high load of larvae in the stool of this HIV positive patient.

Key words: Diarrhea, Feces, HIV Infection, Ivermectin, Strongyloides stercoralis.

\section{Introduction}

Strongyloides stercoralis has been globally neglected for long but is gaining importance in recent times [1]. The concern is more alarming in the immunosuppressed individuals because of the high parasitic load and potentially fatal manifestations observed in these patients.

\section{Case Report}

A 35-year-old male patient presented with complaints of intermittent watery diarrhea (3-4 times/day) for last three months. The patient was a resident of a rural area in Bihar (a state in Northern India). He was diagnosed with HIV four years back. On examination, his abdomen was soft and non- tender with no obvious organomegaly. Routine laboratory investigations revealed mild anemia (10.4 $\mathrm{gm} \%$ ) along with eosinophilia (8\%). His CD4 count estimated by the FACS count system was 16/ mcl. The stool sample of the patient was sent for complete parasitological work up.

Stool was watery with no visible blood, mucus, worm or proglottids. Microscopic examination of the normal saline mount of stool sample revealed an alarmingly high number of motile larvae with a count of $>100$ per low power field [Fig. 1]. They were identified as rhabditiform larvae of Strongyloides stercoralis by their short buccal capsule and the prominent genital primordium. The average length

\section{Corresponding Author: Dr. BR Mirdha} Email: mirdhabr2078@gmail.com

Received: June 23, 2016 | Accepted: September 21, 2016 | Published Online: November 10, 2016 This is an Open Access article distributed under the terms of the Creative Commons Attribution License (creativecommons.org/licenses/by/3.0) Conflict of interest: None declared | Source of funding: Nil | DOl: http://dx.doi.org/10.17659/01.2016.0128 
of larvae on micrometry was about $218 \mu$ (range 203-242 $\mu$ ). The coccidian parasites were negative on modified acid fast stain. No other ova, cyst, or trophozoite were detected in stool. The patient was successfully treated with ivermectin $(200 \mu \mathrm{g} / \mathrm{kg} /$ day) for 2 days.

\section{Discussion}

Strongyloides stercoralis, a soil transmitted helminth, is mostly prevalent in the tropical parts of the world [2]. Man is the only host required for the completion of life cycle of this nematode. The host is infected by the penetration of skin by filariform larvae. After the parasite migrates through the lungs, it matures into an adult female worm in the small intestine. The female worm produces eggs by parthenogenesis. The eggs hatch and produce rhabditiform larvae. The rhabditiform larva is passed into the stool where it matures into the infective filariform larva. The rhabditiform larva may sometimes change into filariform larvae in the intestine itself and penetrate the walls causing autoinfection and therefore, leading to rapid multiplication in the number of larvae [3].

Strongyloidiasis is difficult to diagnose clinically as it presents with nonspecific signs and symptoms [4]. The methods for laboratory diagnosis include microscopic examination of the faeces and serology [5]. Ivermectin is the drug of choice for treatment of strongyloidiasis [5]. The estimated prevalence of strongyloidiasis in India has been found to be $6.6 \%$ and $11.2 \%$ in community and hospital based surveys respectively [1]. Several studies have shown an increase in incidence of infection with Strongyloides stercoralis in HIV infected population but only a handful of cases with severe manifestations have been noted in these individuals $[6,7]$. This is largely because, there is loss of Th1 activity in HIV infection but Th2 activity is well preserved which provides protection against development of severe manifestations [8].

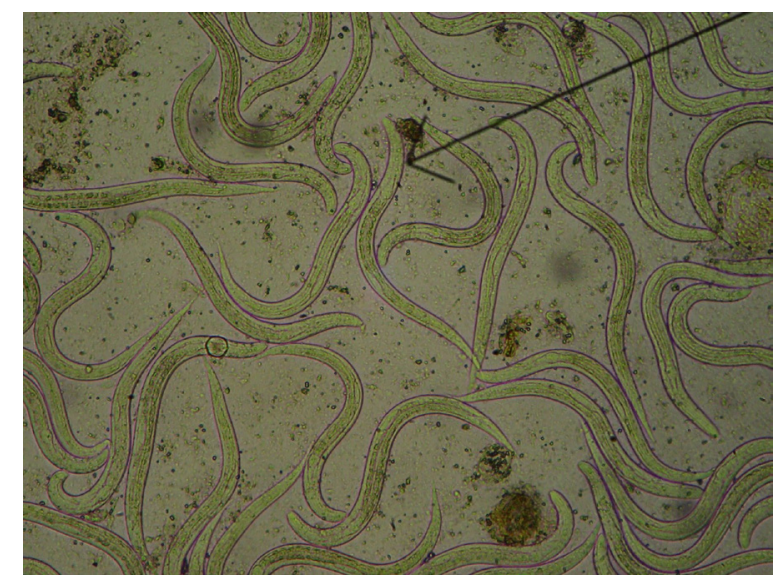

Fig.1: Rhabditiform larvae of S. stercoralis.

\section{Conclusion}

We report this case to demonstrate the unusually high load of larvae in the stool of this HIV positive patient. Parasitological work up (especially for larvae of Strongyloides stercoralis) should therefore, be regularly conducted in immunosuppressed patients presenting with diarrhoea.

\section{References}

1. Schar F, Trostdorf U, Giardina F, Khieu V, Muth S, Marti $\mathrm{H}$, et al. Strongyloides stercoralis: Global Distribution and Risk Factors. PLoS Negl Trop Dis. 2013;7(7):e2288.

2. Buonfrate $D$, Requena-Mendez $A$, Angheben $A$, Munoz J, Gobbi F, Van Den Ende J, et al. Severe strongyloidiasis: a systematic review of case reports. BMC Infect Dis. 2013;13:78.

3. Miller A, Smith ML, Judd JA, Speare R. Strongyloides stercoralis: systematic review of barriers to controlling strongyloidiasis for Australian indigenous communities. PLoS Negl Trop Dis. 2014;8(9):e3141.

4. Segarra-Newnham M. Manifestations, diagnosis, and treatment of Strongyloides stercoralis infection. Ann Pharmacother. 2007;41(12):1992-2001. 
5. Greaves D, Coggle S, Pollard C, Aliyu SH, Moore EM. Strongyloides stercoralis infection. Bmi. 2013;347:f4610.

6. Jongwutiwes U, Waywa D, Silpasakorn S, Wanachiwanawin $D$, Suputtamongkol $Y$. Prevalence and risk factors of acquiring Strongyloides stercoralis infection among patients attending a tertiary hospital in Thailand. Pathog Glob Health. 2014;108(3):137-140.
7. Paboriboune $P$, Phoumindr N, Borel E, Sourinphoumy K, Phaxayaseng S, Luangkhot $E$, et al. Intestinal parasitic infections in HIVinfected patients, Lao People's Democratic Republic. PLoS One. 2014;9(3):e91452.

8. Siegel MO, Simon GL. Is human immunodeficiency virus infection a risk factor for Strongyloides stercoralis hyperinfection and dissemination. PLoS Negl Trop Dis. 2012;6(7):e 1581. 